\title{
Turning with Linear Tangential Tool Shift and Its Results
}

Karol Vasilko

Faculty of Manufacturing Technology Technical university of Košice, Bayerova 1, SR. karol.vasilko@tuke.sk

Machining, mainly turning, si characterised by the highest labour input among the technological methods. This leads to the conditin when, for instance, in line production at hammering power press, which produces forginngs in the stroke of 1 second, tens of lathes follow and their gradual turning with the stroke of tens of seconds up to minutes. Whole history of material machining has been lead with the effort to shorten machining time by the improvement of cutting materials, tool geometry, integration of machining of several workpiece areas in one stroke, etc. The article analyzes an effectiv way to signaficantly sorten machine time, based on the application of turning with tangential tool feed versus workpiece. Inaddition, the method integrates roughing and finishing into one operation and ensures high quality of machined workpiece surface.

Keywords: turning, machining time, tangetial shift, quality of machined surface

\section{Introduction}

The well-known obstacle cutting machine time is known relationship:

$$
\tau_{s}=\frac{l}{n . f}
$$

Where:

$l$ is the lenght of machined area, mm,

$n$ - frequency of workpiece turning, $\min ^{-1}$,

$f$ - shift, mm.

Or after substitution for $n$ from the formula $v_{c}=\frac{\pi \cdot D \cdot n}{1000}$,

$$
\tau=\frac{l}{1000 . v_{c} \pi \cdot D},
$$

where:

$v_{\mathrm{c}}$ is cutting speed, $\mathrm{m} \cdot \mathrm{min}^{-1}$,

$D$ - area diameter, $\mathrm{mm}$.

It means that cutting speed is the parameter which can influence machining time.

This has lead to the efforts to increase cutting speed. However, when turning steel, this option has been limited mainly due to the reason that the tool durability has been sharply decreasing (Tailor $T-v_{\mathrm{c}}$ formula). This is the reason why the terms as ,optimal cutting speed from the viewpoint of tool durability“ or ,optimal cutting speed from the viewpoint of maximum productiveness" have been implemented.

Another technological parameter influencing machining time is the shift, which has lead to the term ,hihgshift machining". However, it application requires a considerable interference into the tool geometry ort he application of different kinematics of machining. In previous works [1], [2], [3], [4] there occur suggestions for different mutual arrangement and solving of mutual tool and workpiece movements in the space on theoretical as well as realisational levels. Single-purpose machines have been developed, such as the one for circular turning of combination tools [5], milling of rotary surfaces [6] of workpieces.

\section{Definition of applied technological principle}

For turning, the hopes have been put into so-called tangential turning. This interesting way continues as follows, on theoretical and practical levels.

In Fig. 1 there is the basic principle of turning with linear tangential tool shift.

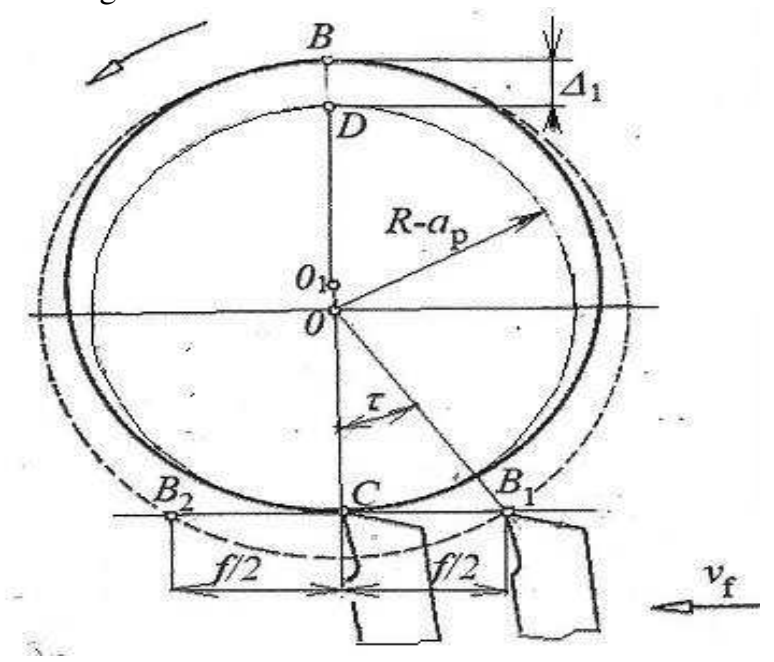

Fig. 1 Principle of turning with tangential tools shift, related to one tool shift.

The analysis of kinematic characteristics has proved that the surface creation, for this turning method, falls within different laws than within the lengthwise turning. Therefore it is necessary to pay closer attention to this problem from the viewpoint of following the prescribed metrological characteristics of machined area. During lengthwise turning, the workpiece surface is created by copying the cutting tool shape. Presuming the tool tip is rounded, for the maximum height of profilen uneveness the well-known theoretical formula applies:

$$
R z=\frac{f^{2}}{8 . r_{\varepsilon}}
$$

Where:

$f$ is the shift, mm,

$r_{\varepsilon}$ - corner radius, $\mathrm{mm}$ 
Any increase of the shift in the effort of shortening the machining time, however, leads to the steep increase of $R z$. Ceratin compensation of this fact is possible by the increase of the tool tip radius.

When turning with tangential shift, the machined surface is formed by copying the linear cutting edge, similarly to cutting-off turning. It means that the uneveness of machined surface copy only the microuneveness of the tool's cutting edge. Because the position of the cutting edge against the workpiece changes and each point of the cutting edge, which creates one lateral cross-cut section of the workpiece only in one point, $C$, see Fig.1. Considering fluent movement of tool's cutting edge along the tangent line towards this diameter and uninterrupted workpiece movement, each cross-cut section is oval. The oval is formed by two sub-circuits of relative course, which intersect in point $B$.

The trajectories of relative tool movement in the cross-cut workpiece section a tone turn is shown by the curve $B C$. The value of lateral shape variation can be determined from the triangle $O B_{l} C$ [7].

$$
\Delta_{1}=\sqrt{\left(R-a_{\mathrm{p}}\right)-\frac{f^{2}}{4}}-\left(R-a_{\mathrm{p}}\right) \text {. }
$$

If the tool's cutting edge is not parallel with the workpiece axis, i.e. $\lambda_{\mathrm{s}} \neq 0$, a hyperboloid is formed on the machined surface during the shift.

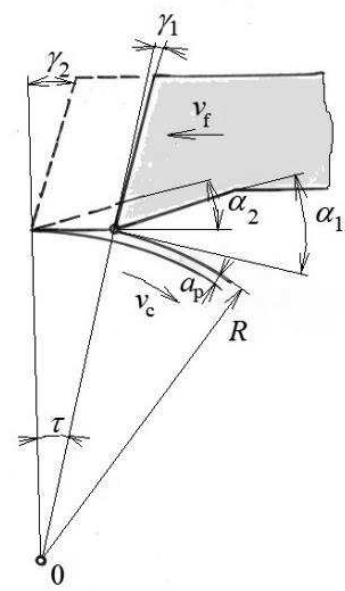

a)

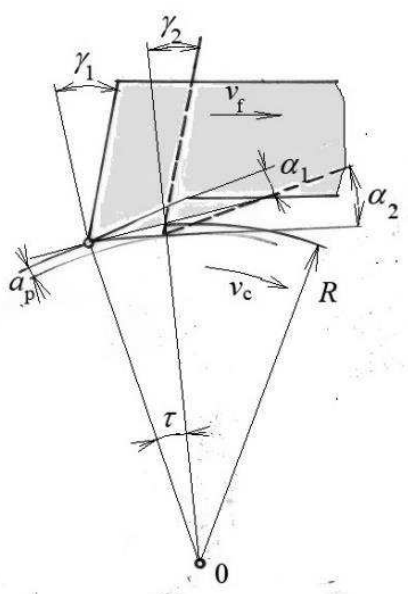

b)
Fig. 2 Tool tangential feed options: a - contradirectio$n a l, b$ - - codirectional
It is necessary to present the fact that this method of turning can be realised with the shift at the direction, or against the direction of the vector of cutting speed, like codirectional or contradirectional turning. Both cases differ mainly by the change of work geometry. In Fig. 2 both cases are shown.

In the first case, when the tool moves into the position of workpiece axis, there occurs a work increase of face angle. This method suits the turning of materials with higher rigidity and hardness, turning of casts with crust, forgings. The other method (b) starts with large working face angle $\left(\gamma_{1}\right)$ therefore it is suitable for turning non-ferrous and light metals.

\section{Experimental verification}

The verification of turning results has been performed by a model tool, see Fig.3. The tool is clamped in a jig that allows for rake angles and tool anglesettings.

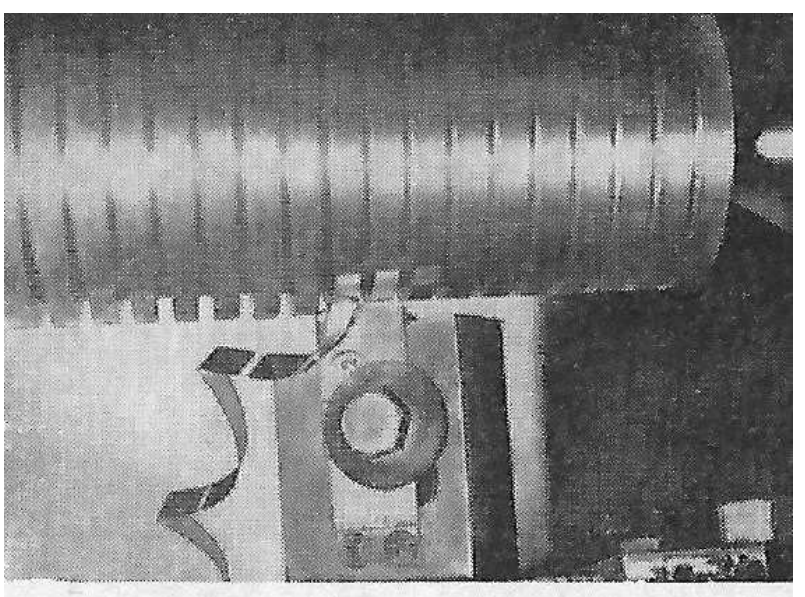

Fig. 3 Model turning with tangential tool shift.

Turning, see Fig. 3, has been performed with the shift $1 \mathrm{~mm}$ per turn, at the frequency of workpiece rotation 355 min $^{-1}$, workpiece diameter $80 \mathrm{~mm}$, and cutting speed 90 $\mathrm{m} . \mathrm{min}^{-1}$. A workpiece section of width $5 \mathrm{~mm}$ and cut depth $1 \mathrm{~mm}$ has been turned. Time to turn one workpiece section, which has been recorded - 1,25 s.

It can be seen that the turned sections are mirror-like shiny, similarly to classical cut-off turning. This means it is a typical free cut. An example of a particular surface profile recording is shown in Fig.4.

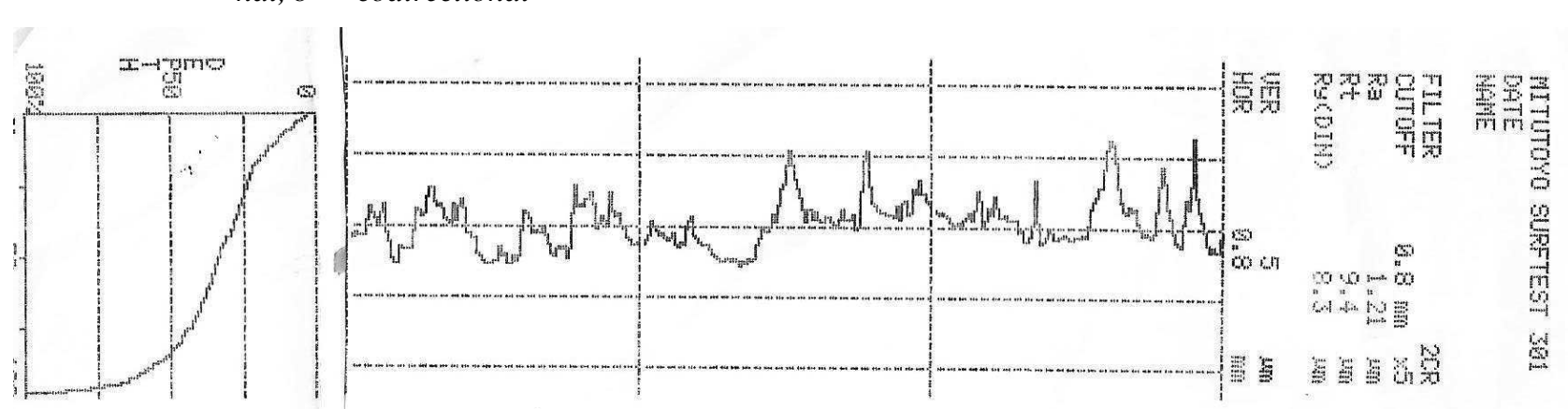

Fig. 4 Recording of profile of machined surface when turning with tangential shift. 
In Tab. 1 there are the results of the evaluation of circularity errors depending on the cutting plate face angle in use. Cutting conditions: workpiece: 100Cr6; tool: P20; $v_{\mathrm{c}}=90 \mathrm{~m} \cdot \mathrm{min}^{-1} ; a_{\mathrm{p}}=2.5 \mathrm{~mm} ; f=0.635 \mathrm{~mm}$

Tab. 1 Experimental dependence of circularity and waviness errors of machined surface on face angle.

\begin{tabular}{|c|c|c|}
\hline $\begin{array}{c}\text { Face angle } \gamma_{\mathrm{n}} \\
0\end{array}$ & $\begin{array}{c}\text { Circularity error, } \\
\mu \mathrm{m}\end{array}$ & Waviness, $\mu \mathrm{m}$ \\
\hline 0 & 23 & 19 \\
\hline 5 & 20 & 17 \\
\hline 10 & 17 & 14 \\
\hline 20 & 14 & 12 \\
\hline 25 & 10 & 8 \\
\hline
\end{tabular}

Both parameters decrease with increasing face angle. Similarly, the influence of cutting edge incline angle has been evaluated. Corresponding result is shown in Fig. 2.

Tab. 2 Experimental dependence of circularity error and waviness of machined surface on cutting edge incline angle

\begin{tabular}{|c|c|c|}
\hline $\begin{array}{c}\text { Cutting edge inc- } \\
\text { line angle, } \lambda_{\mathrm{s}},{ }^{0}\end{array}$ & $\begin{array}{c}\text { Circularity er- } \\
\text { ror, } \mu \mathrm{m}\end{array}$ & $\begin{array}{c}\text { Waviness, } \\
\mu \mathrm{m}\end{array}$ \\
\hline 50 & 22 & 25 \\
\hline 45 & 18 & 20 \\
\hline 40 & 20 & 28 \\
\hline 35 & 20 & 28 \\
\hline 30 & 15 & 12.5 \\
\hline 25 & 17.5 & 8 \\
\hline 20 & 12 & 6 \\
\hline 15 & 15 & 14 \\
\hline 10 & 10 & 12 \\
\hline 5 & 10 & 15 \\
\hline & & \\
\hline
\end{tabular}

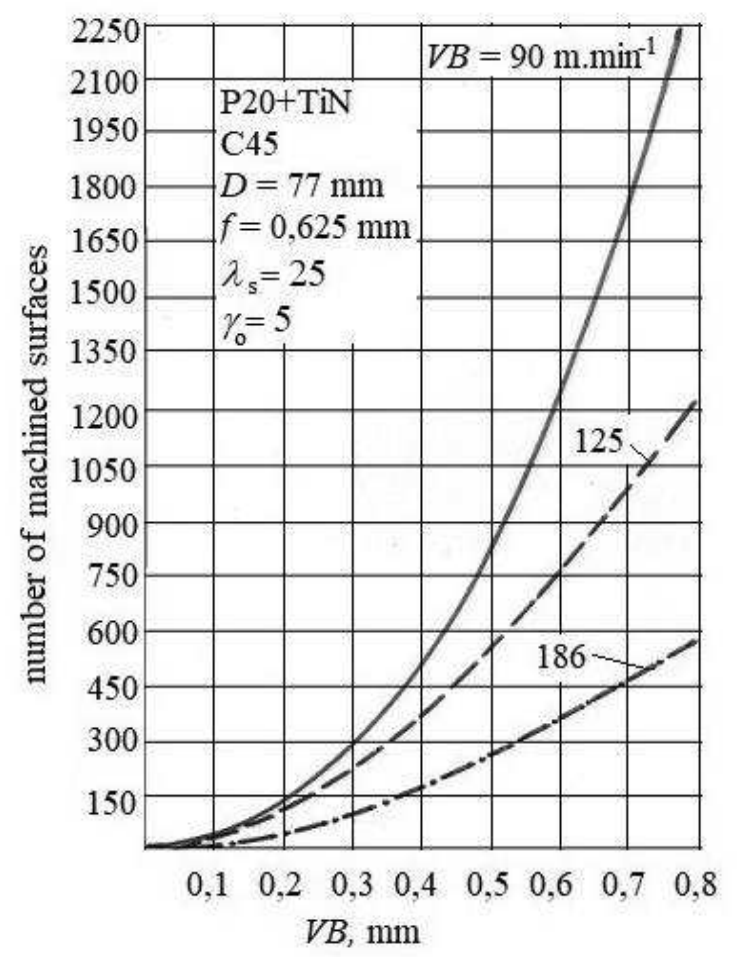

Fig. 5 Deendence between tool land wear on tool count.
Equally, with growing angle $\lambda_{\mathrm{s}}$, circularity error decreases and waviness behaves variably. Both observed parameters can be selected according to the presented recommendations.

AS can be assumed, a short toolnengagement time will lead to a low tool wear rate. Machining tests were performed to determine tool wear on the land deending on the number of tool shots. The result is shown in Fig. 5 .

\section{Sample of practical realisation}

In Fig. 6 there is an example of the application of turning with linear tangential shift in practice. There is turning of seven face, outer rotation and shape areas of double-forging on the rings of a roller bearing according to Fig. 6.

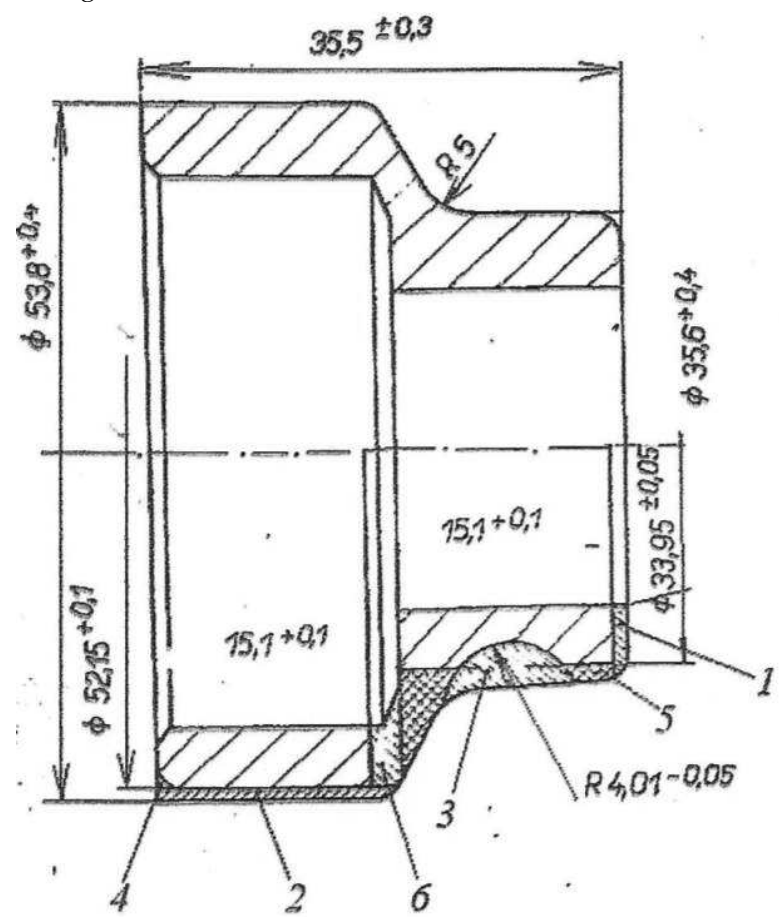

Fig. 6 Drawing of a double-forging of a roller bearing (type symbol 6305 with marked cut-off allowances by different tools.

Internal areas have been turned by a combination tool (Fig. 7). Cutting plates are set to the dimensions by micrometric bolts.

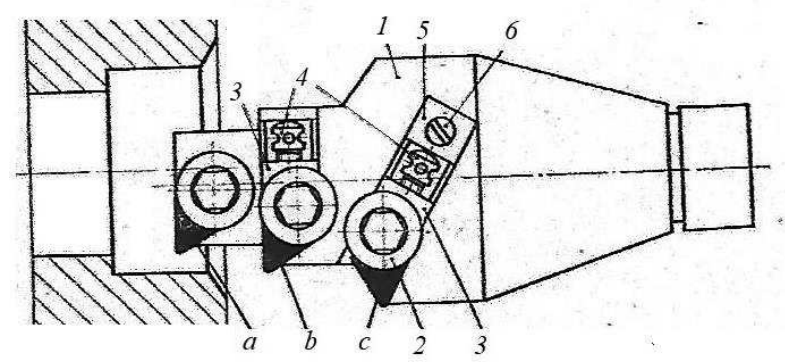

Fig. 7 Tool for combination turning of itnernal sreas of workpiece from Fig. 4. a,b,c-cutting plates, 1- tool body, 2- clamping bolt, 3- setting element, 4- setting screw, 5- headrest, 6- clamping screw, 
A view of the actual tool is shown in Fig. 8.

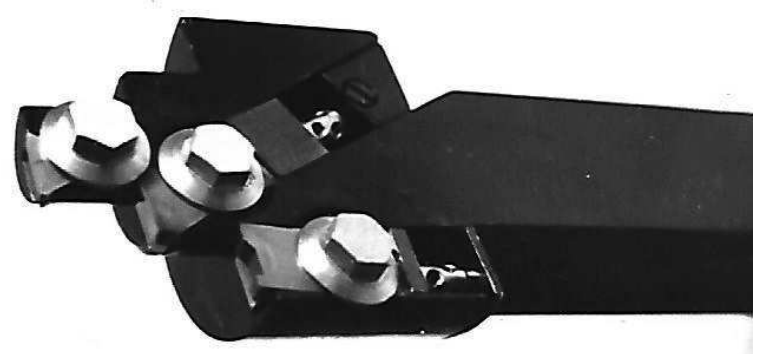

Fig. 8 Combination tool for simultaneous turning of internal workpiece areas.

Such turned forging is clamped into the distance pin in the lathe spindle. A view of the second operationu tangential turning of outer areas is shown in Fig. 10. A block tool with cutting plates, the position of which corresponds with the dimensions of different machined areas, is clamped on the lateral support of the machine. When the support passes into its final position, all outer areas of the forging are finally machined.

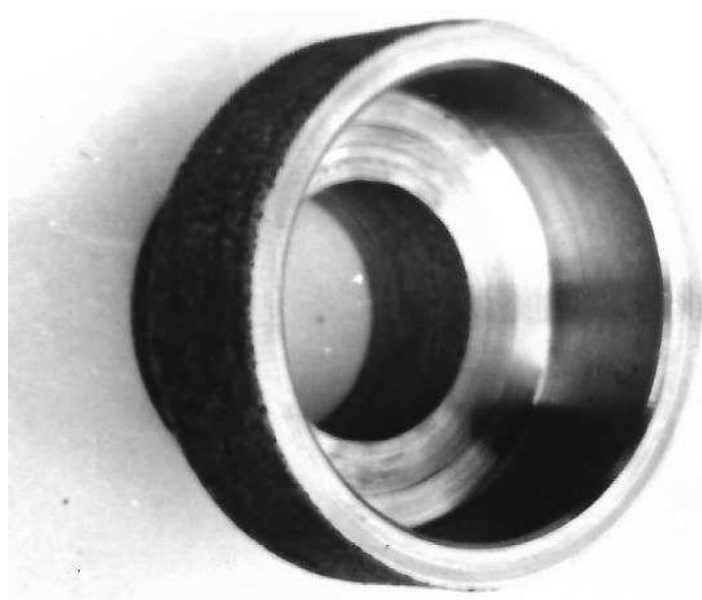

Fig. 9 Workpiece after the first operation

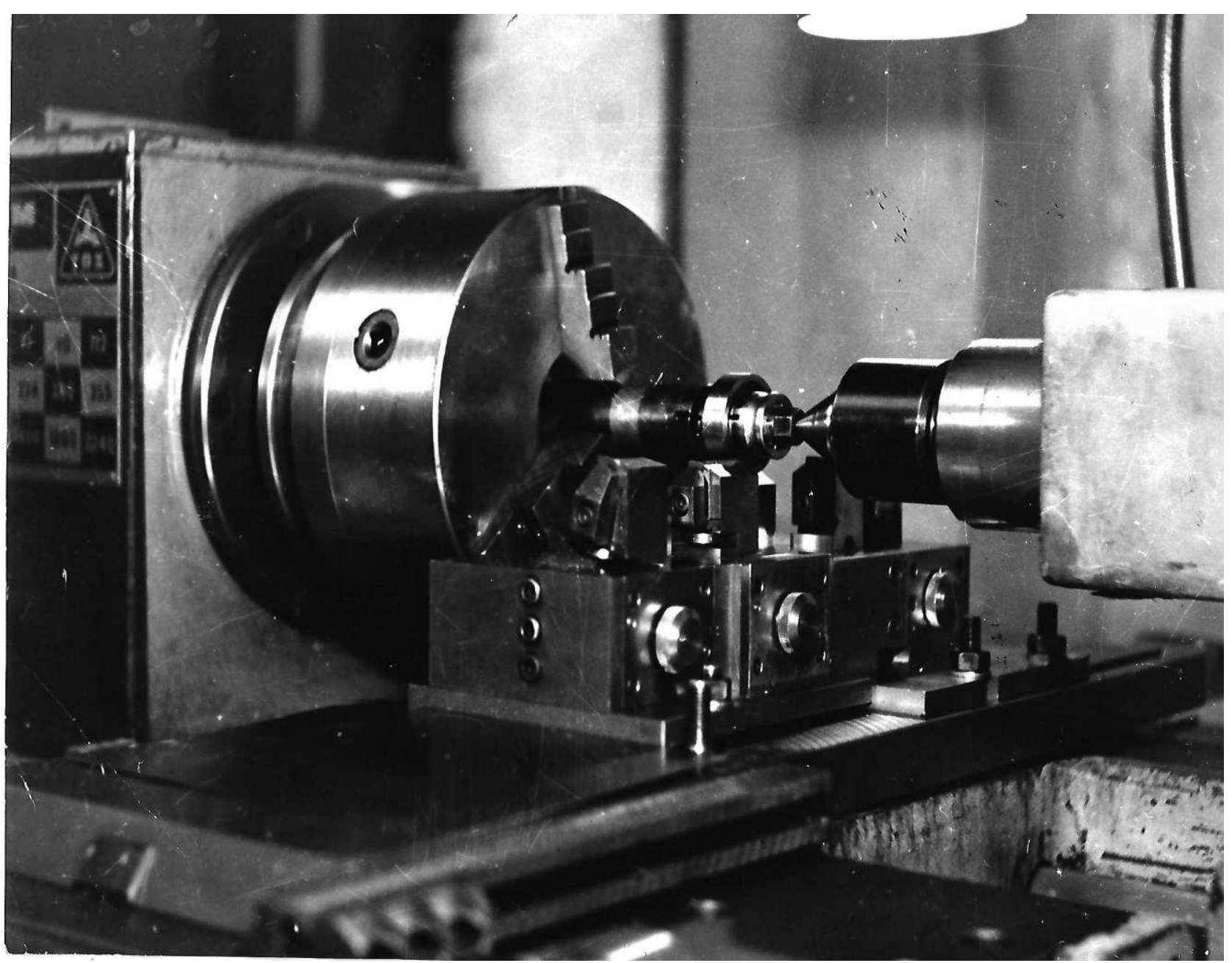

Fig. 10 View of turning of the double-forging to become the rings of a roller bearing by a combination tool during machining

A detail of a part of tool block is shown in Fig.11. Different cutting plates are set for the dimensions outside the machine.

When the tool passes under the workpiece, all basic areas are finished in turning. What is missing is the impaction of the edge on outer and itnernal rings and the circular orbit of the outer ring. They must be done on a different lathe. 


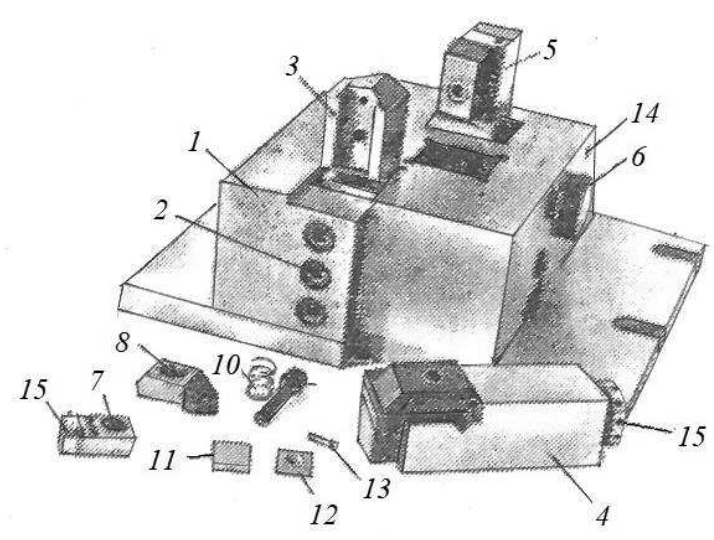

Fig. 11 Design of a tool block with setting elements to set different tools into the dimensions. 1 - tool body, 2clamping screws, 3,4,5 - knife holders, 6 - setting bolt, 7 - setting element, 8 -clamp, 10 - spring, 11 - cutting plate, 12 -washer, 13 -screw, 14 - screws for block clamping, 15, 16 - setting bolts.

The result of measuring of netto machining time, when turning different areas of the forging, is shown in Tab. 3.

Tab. 3 Values $\tau_{\mathrm{s}}$ when turning of different areas of for-

\begin{tabular}{|c|c|}
\hline Surface & $\mathrm{s}$ \\
\hline 1- itnernal ring face & 5 \\
\hline $\begin{array}{l}\text { 2- cylinder surface of outer } \\
\text { ring }\end{array}$ & 5 \\
\hline $\begin{array}{l}\text { 3- circular orbit of internal } \\
\text { ring }\end{array}$ & 5 \\
\hline $\begin{array}{l}4-\text { edge rounding of outer } \\
\text { ring }\end{array}$ & 3 \\
\hline $\begin{array}{l}5 \text { - cylinder surface of it- } \\
\text { nernal ring }\end{array}$ & 5.5 \\
\hline $\begin{array}{l}6-\text { outer ring face and spa- } \\
\text { cing }\end{array}$ & 6 \\
\hline
\end{tabular}

In Fig. 12 there is a view of turned rings of a roller bearing with a chip from different surfaces.
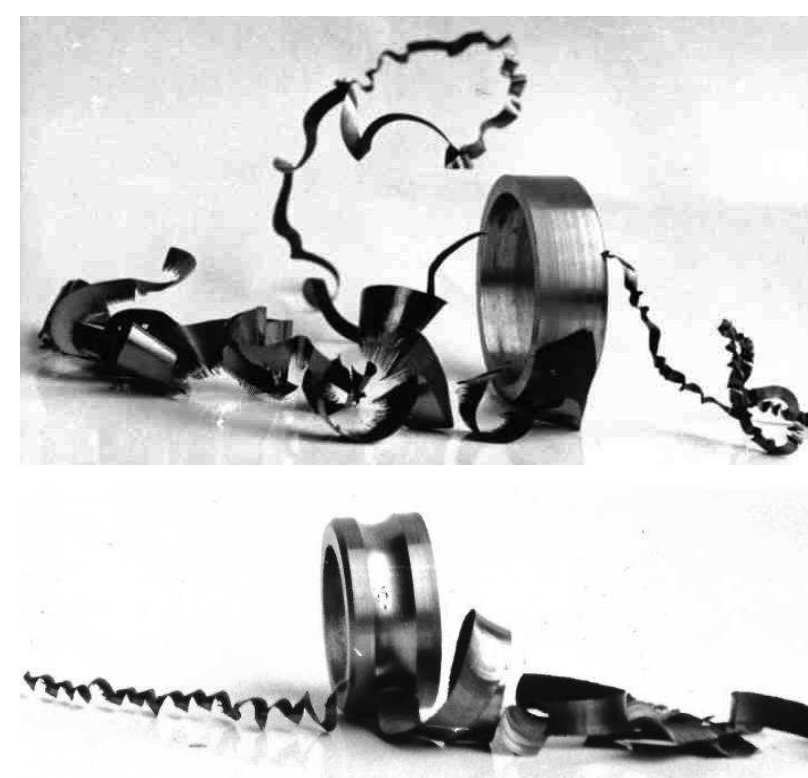

Fig. 12 Turned rings and chip obtained from different surfaces.

What is peculiar about tangential turning, when the tool has a linear cutting edge, is the fact that in the point of first contact of the cutting edge with turned surface, the thickness of the cut-off layer equals zero. As a result of this, the thickness of the chip lengthwise changes. The chip profile in the cross-cut section looks triangle-like. Its thickness is very small and gradually changes to zero (left figure of the chip from outer diameter). This leads to its natural spiralling. The chip is segmented, its rigidity is very low and it breaks when touches any obstruction in the turning machine. Similar chip is formed during tangential turning of the shape surfac (right figure). Small, spiralling chips in the figure come from edge impaction and tangential face turning.

Orientation measurement of cutting forces has been performed on the widest section of the workpiece (outer diameter of outer ring, width $15 \mathrm{~mm}$ ). In Fig. 13 there is a recording of the course of all elements of cutting force during a single shift of the tool.

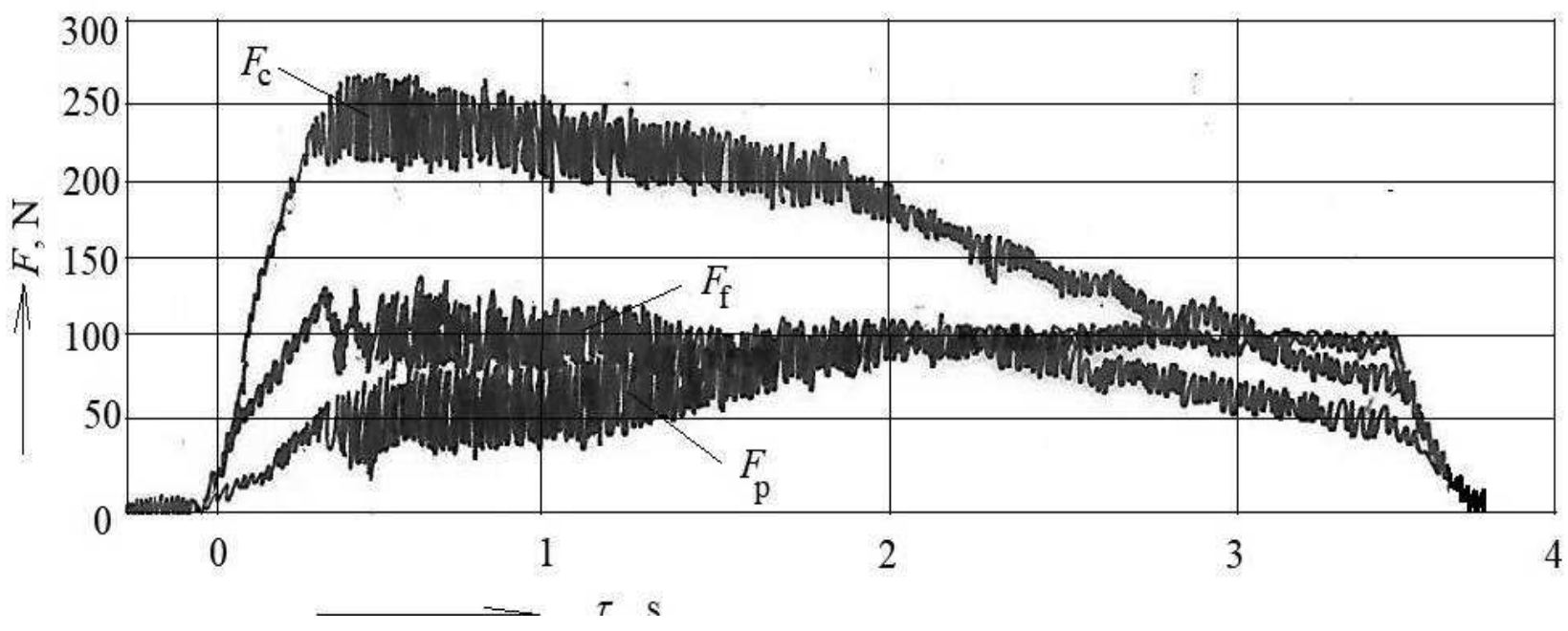

Fig. 13 Course of cutting forces during tangential turning. workpiece: steel 100Cr6, tool: P20, $a_{p}=1,65 \mathrm{~mm} ; f=0,65$ $\mathrm{mm}, \mathrm{n}=600 \mathrm{~min}^{-1},\left(v_{c}=76 \mathrm{~m} \cdot \mathrm{min}^{-1}\right) ; \lambda_{\mathrm{s}}=30^{0}$ 
As a result of the change of the thickness of the cutoff layer, at the beginning there occurs a steep increase of all three elements of the cutting force. After reaching maximum thickness of taken-off layer, the cutting forces continually decrease to zero.

\section{Conclusion}

New characteristics and results of turning can be characterised for the observed specific tool and workpiece arrangement.

Positives:

- Short toolpath in the workpiece and machine time results in a low tool wear ratedepending on the number of shorts.

- $\quad R z$ practically does not depend on $f$, only on the quality of tool cutting edge

- Large shift and short tool track lead to considerable shortening of machining time

- Possibility to turn multiple workpiece surfaces in one shift

- Exclusion of the division into roughing and finishing shifts

Negatives:

- Method requires special tool arrangement on the turning machine.

- Small shifts (under $0.2 \mathrm{~mm}$ ) are not suitable a small thickness of the cutlayer to self-extited oscilations in the technological system.

- I tis necessary to check and limit the deviation of the rounded area.

\section{References}

[1] ETIN, A.O. (1964). Kinematičeskij analiz metodov obrabotki rezanijem. Moskva, Mašinostrojenije, 1964.
[2] FILE, L. (1970). Metal removal by skiving on turning machines. Machinery and production engineering, 2911, 1970.

[3] KANEVCOV, V. M., BosinZA, A. J. (1961). Tangencial'noje točenije vnutrennych poverchnostej. In: Trudy instituta VNIIPP, 26, Moskva, 1961 No. 2

[4] LADANY, Sh. (1972). Die wirtscaftlichan Aspekte des Drehens mit spiralförmigem Drehwerkzeug. Microtechnic č. 8, 1972.

[5] ŠAUMJAN, G. A., JERAMAKOV, J. M. (1970). Opredelenije tolštiny sreza pri točenii Otverstvij s krugovoj podačej. Izvesija VUZMašinostrojenije, Nr. 5, 1970.

[6] LOLADZE, T. N. (1989). Základy optimalizácie strojárskej technológie. Bratislava, ALFA, 1989, 216 s., ISBN 80-05-00083-9

[7] JERZAK, J et al. (2010). Surface integrity of hardened bearing steel after milling. Manufacturing Technology, Vol 10, 2010, pp. 80-87.

[8] VAsilKO, K., STROJNÝ, M. Progresívne metódy sústruženia. Bratislava, ALFA, 1077, 208 $\mathrm{s}$.

[9] MAŇKOVA, I. (2000). Progresívne technológie. Košice, Vienala, 2000, 275 s., ISBN 80-7099-4304

[10] KUNDRÁK, J., PÁLMAI, Z. (2019). The Change of Tool Life in a Wide Range of Cutting Speeds in Hard Turning. Manufacturing Technology, April 2019, Vol. 19, No.2

[11] JERSAK, J. et al. (2012). The Integrity of th Surface after Millingof uenched Bearing Steel. Manufacturing Technology, No. 4, 2012, pp.13-20 